\title{
Vineyard acreage simulations in consideration of climatic changes affecting Rhineland-Palatinate (RLP)
}

\author{
Marc Dressler ${ }^{1}$ and Jürgen Oberhofer ${ }^{2}$ \\ ${ }^{1}$ Ludwigshafen University / DLR Rheinpfalz (Rhineland-Palatinate Service Centre for Rural Regions), Professor for \\ Business \& Entrepreneurship, 67435 Neustadt/Weinstraße, Germany \\ ${ }^{2}$ DLR Rheinpfalz (Rhineland-Palatinate Service Centre for Rural Regions), 67435 Neustadt/Weinstraße, Germany
}

\begin{abstract}
An interdisciplinary research project has determined the predictable potential areas suitable for vineyard use in Rhineland-Palatinate by means of the application of the latest available data and in consideration of climatic changes. The objective was to identify the maximum acreage potential with suitability for viniculture in Rhineland-Palatinate as a theoretical high-case scenario for liberalisation. For this purpose an acreage simulation model was developed and validated to capture and consolidate climate data, simulation runs of regional climate models, geodata, the automated land property map and actual measuring data on frost damage. Full account was taken of anthropogenic, climatic and pedological selection criteria. Finally a GIS-based data blending with the suitable areas yielded the potential acreage for viniculture in Rhineland-Palatinate. The model estimates an additional acreage potential with suitability for viniculture of 335,000 acres (135,000 ha) in Rhineland-Palatinate. The analyses further underline the potential for state-of-the art risk management and data based managerial decision making to counter climate induced challenges.
\end{abstract}

\section{Introduction}

Wine is produced on roughly 7.5 million ha cropland generating an output of approximately 250 million hectoliters of wine yearly [1]. The vineyards decrease, coming from a historical maximum of more than 7.9 million ha yielding 300 million hectoliters [2,3]. The supply reduction intentionally prevented of an excess supply, since the annual consumption amounts to approximately 243 million hectoliters. After a continuous increase of consumption - for instance from 226 million hectoliters in 2000 to 255 million hectoliters in 2007 - and a subsequent decrease, the consumption seems to reach a plateau on the contemporary level. Nevertheless, the first impression of a stable market is deceiving, since there are massive changes with diverging regional developments opposing this semblance. While the cultivation and the production volume is decreasing in the "old wine world" of European countries with a long production history, such as France, Spain and Italy, the new wine producers, like China, Chile and New Zealand enhance their capacities and output. Thus, Europe's global production share has decreased from $75 \%$ to approximately $65 \%[2,4]$.

German as well as EU efforts to create market equilibrium and quality oriented and efficient production of wine resulted in restrictions on planting as well as quality requirements also impacting the output. Indeed, wine quality has improved and after years of mass production German producers are again perceived for quality, regaining adequate market recognition for their products, and fostering client relationships locally, regionally, and globally [5].

Current efforts of the European community towards a more liberal market especially for plantation are at present a controversial subject of discussion [6-13]. There is frequently a lack of well-attested data and facts about possible implications of such efforts [14]. This paper contributes to the discussion of liberalization but also to vine cultivation in the light of climate changes since it addresses the question of what acreage potentials for vinicultural use exist in principle in Rhineland-Palatinate in consideration of climate changes. Indeed, climate change influences agrarian usage of cropland [15] and has major impact on vine cultivation [16-18] and the wine market [19].

The research project is being carried out in cooperation and with data management by the Institute for Agroecology (IfA) of the RLP AgroScience (Rhineland-Palatinate). The objective of this interdisciplinary research project was to identify the maximum acreage potential with suitability for viniculture in Rhineland-Palatinate and thus to create a theoretical high-case scenario for reviewing liberalisation models. The approach was made by using a data model basing on the existent crop area and gradual exclusion of areas not fulfilling the required criteria for vine cultivation simulating the impact of climate change and vegetational impacts. Insights gained by experts in viniculture in respect of the needs of the vines were applied and on this basis iterative simulation runs were carried out with vinicultural minimum requirements of various criteria which allow the acreage potential with optimum suitability to be determined.

\section{Model basis}

The total agricultural area in Rhineland-Palatinate built the starting point and therefore the maximum theoretical acreage. An initial reduction in potential was effected by 


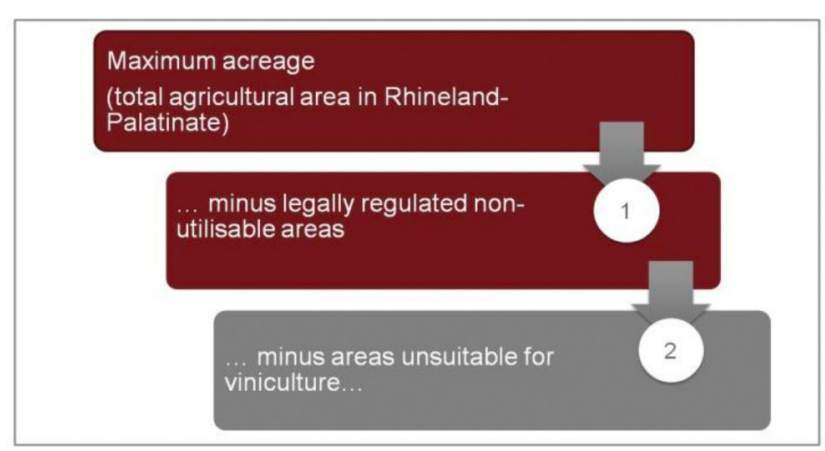

Figure 1. Basic logic of potential acreage analysis.

means of excluding land rendered unsuitable for anthropogenic reasons, especially areas worthy of protection such as FFH (flora and fauna habitat) and bird sanctuaries, nature protection reserves and biotope cadastre areas, as well as land subject to the prohibition on the ploughing up of grassland in sensitive areas.

In the second step the vinicultural requirements were established in detail and integrated into the model via relevant criteria (Huglin index, risks of spring frost [20] and winter frost [21], water availability in the soil) and defined threshold values so that the remaining result indicated the maximum area potential (see Illustration 1) [22].

The original research approach of capturing the acreage potential by means of queries addressed to local experts and the integration of climate data did not yield a valid result [23]. Depending on the respondent as well as the local data availability the acreage with potential for vinicultural use was rated very heterogeneously. Neither did this combination of climate data and survey queries result in any determination of potential areas. It was not possible to localise and forecast cold air phenomena adequately owing to the measurement being carried out only once a day and to the rough nature of the data - areas depicted in $1 \mathrm{~km}$ squares.

As a consequence an area simulation model was developed which collated climate data, geodata, land property map and spatial landscape information [24]. The model was tested against real data, e.g. frost damages on a rated

\section{Fossil Fuel Emissions: Actual vs. IPCC Scenarios}

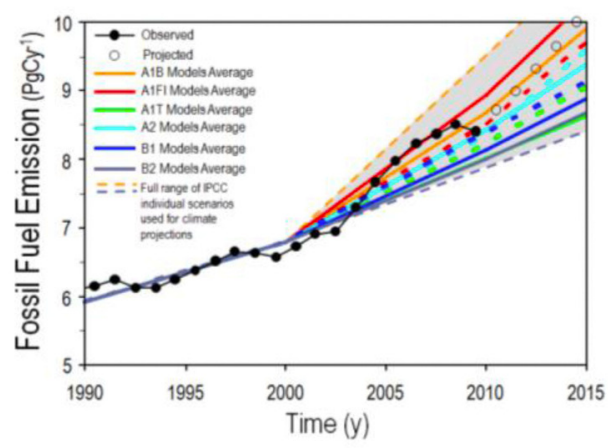

Figure 2. SRES emission scenarios for the $21^{\text {st }}$ century - global warming.

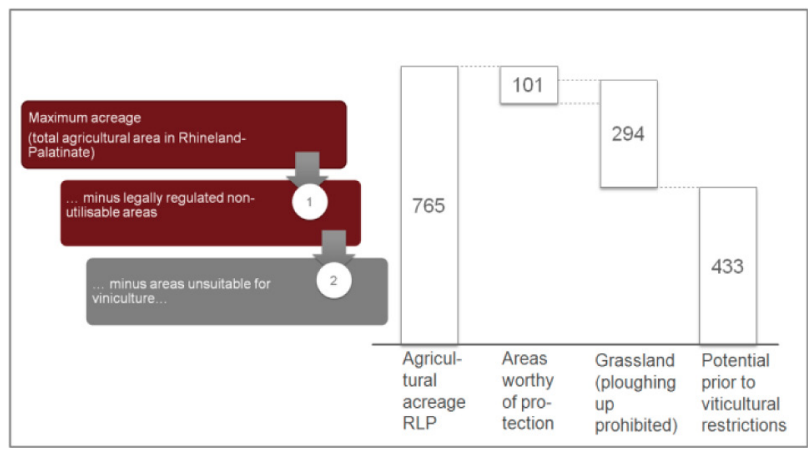

Figure 3. Analysis of area potential taking anthropogenic restrictions into account (in 1000 ha $=2471$ acres).

property. It was not until this combination of data from various sources had been effected that a valid scenario was achieved. In the course of the iterative analyses a digital elevation model was evaluated and analysed as an integral part of the algorithm for the express purpose of determining the areas threatened by frost. The spatial resolution of $20 \times 20 \mathrm{~m}$ permitted forecast projections on the basis of (partial) cadastral units [25].

The model is based on two simulation runs of the WETTREG Climate Service Centre 2006 regional climate model in the SRES A1B climate scenario [26×27]. The reason for making use of the A1B scenario in the research project was the fact that among all the available scenarios it is the one which approximately reflects the development of atmospheric $\mathrm{CO}_{2}$ concentrations as currently observed. The model runs effected represent very clear changes which can be deemed to be worst case projections within scenario A1B.

\section{Vineyard acreage potential in the model test}

Assuming a theoretical area of suitability (all agricultural areas according to the official land property map) in Rhineland-Palatinate amounting to $1,900,000$ acres (765,000 ha) and deducting any areas worthy of protection there remains a fundamentally conceivable theoretical area potential of 1,070,000 acres (433,000 ha).

For purposes of determining the vinicultural suitability of this theoretical acreage potential a combination of requirements was defined consisting of the temperature requirement of the vine (Huglin index [28]), the avoidance of winter frosts and spring frosts, a minimum supply of soil water available to the plants (utilisable field moisture capacity) and a minimum coherent area for economically viable cultivation. In this way full account was taken of decisive requirements both in terms of viniculture and of business.

\subsection{Ascertaining a thermal vinicultural threshold}

The determination of a threshold value on the basis of the Huglin index to ensure adequate growing degree days for the vines proved to be difficult. The investigations showed that an approach assuming a Huglin index value of at least 1500, as recommended in the pertinent literature 
[17], would classify a large part of the area currently used as unsuitable. The reasons for this are to be found in the structure of the climate data applied and the calculation method of the Huglin index, neither of which take into consideration the influence of the partly complex topography of the terrain [29]. In order to compensate for these influences the potential insolation separately calculated from the elevation model for each individual cadastral unit was integrated into the algorithm to ascertain vinicultural suitability. The validation of the pool of areas suitable for vines with consideration of this parameter led to a realistic depiction of the suitability of the areas currently cultivated and thus also promises valid simulations of future scenarios in the model [30].

\subsection{Simulation of frost risks}

Besides the considerations of mean temperature requirements the aspect of minimum temperatures (winter frosts and spring frosts) [31] are of great significance in the question of vinicultural suitability [32,33]. The depiction of frost risks on the basis of interpolated climate data presents major difficulties owing to the temporal and spatial dynamics of frost occurrences (cold air flows) [29,30]. This challenge was met by the use of a GIS-based analysis of the elevation relief. The "relative elevation" relief parameter derived from the digital elevation model specifies per pixel the elevation above the lowest line of the terrain. By taking this parameter into account it is possible to identify pockets of cold air and areas of cold air flow and to exclude them in the model (areas with relative elevations of $<3 \mathrm{~m}$ ) [34]. A damage mapping of the severe frost occurrence in May 2011 and consultation with experts from the viniculture sector of the DLR Rheinpfalz (Rhineland-Palatinate Service Centre for Rural Regions) resulted in a successful validation of the analysis of areas with frost risk.

\subsection{Soil water available to the plants}

The assessment of the suitability for vinicultural usage has to take not only the climatic restrictions but also the soil conditions into account [35]. The so-called field moisture capacity is of particular significance here. The concept "utilisable field moisture capacity" is understood to denote that part of the field moisture capacity which is

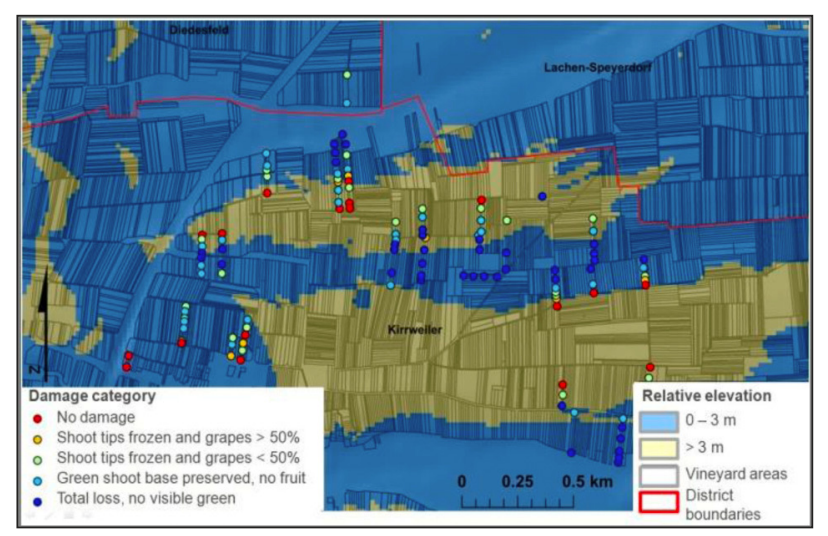

Figure 4. Frost risks exemplified by Kirrweiler in the district of Kirrweiler. available for and can be utilised by the vegetation. As a threshold value for the vinicultural suitability of a location all areas $>90 \mathrm{~mm}$ (threshold value for a medium utilisable field moisture capacity) were considered. Locations with a utilisable field moisture capacity of $\leq 90 \mathrm{~mm}$ were regarded as viniculturally unsuitable.

\subsection{Minimum size for commercial viability}

A coherent area of $1000 \mathrm{~m}^{2}$ was defined as the threshold value for a commercially viable minimum size.

\section{Results}

Taking into consideration the criteria and threshold values stated and working on the basis of an A1B-normal climate scenario (WETTREG Climate Service Centre 2006) determined an additional acreage potential with suitability for viniculture of 335,000 acres (135,000 ha). Therefore the total potential for viniculture calculated by adding the potential future acreage to the existing vineyard areas of 163,000 acres $(66,000 \mathrm{ha})$ results in a theoretical possibility of approximately 498,000 acres (200,000 ha) overall vineyard area in Rhineland-Palatinate. However, it has to be pointed out that the simulation on which the research was based represents merely one of many possible future climatic developments and can therefore only be interpreted as one of several possibilities.

The ascertainment of the acreage potential showed that a large part of the maximum theoretically possible area (initial area) did not fulfil the temperature requirements of the vines. This resulted in the necessity of excluding more than half the acreage. The risk of frost excluded a further third of the acreage potential. However, the criteria of the availability of soil water to the plants and minimum size made only a slight reduction to the potential.

In the event of liberalisation in respect of the statutory regulation of planting rights the vineyard acreage in Rhineland-Palatinate could in an extreme case be more than tripled. Viniculture could expand over larger areas in the established wine-growing areas (e.g. Rhine-Hesse, Mosel, Palatinate) and besides these traditional vinicultural regions vineyards could be planted to a greater extent in new locations such as the Saar-Nahe uplands. In view of the defined vinicultural conditions the "new vineyard acreage" could substitute for existing wine-growing areas

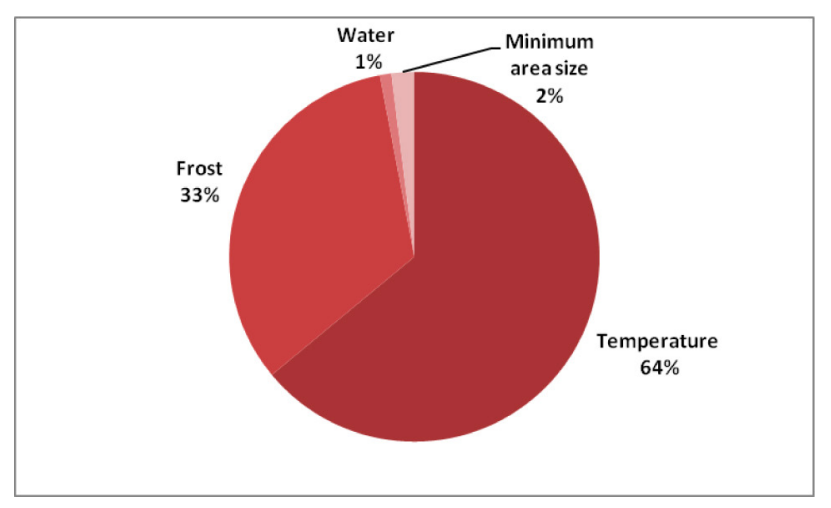

Figure 5. Vinicultural restrictions and acreage potential. 
and in this way also increase efficiency because of a higher suitability of the substitution acreage.

The vinicultural utilisation of additional land would cause a reduction in other agricultural crops and presupposes entrepreneurs willing to take an economic risk in consideration of the business viability in investment decisions. Indeed, a reduction of crop area aggravates the restrictions [36]. Already at this point we are beginning to anticipate that the current profitability of the sector does not suggest that any considerable part of the acreage potential determined would be immediately developed and planted on a commercial scale [37-39]. However the ascertainment of the functions of supply and demand is an integral prerequisite for market efficiency and should guide political decision making - with a long-term perspective.

Within the framework of the analyses further simulations were carried out to test the sensitivity of the results. On the one hand calculations were made with different scenarios and varying threshold values, on the other hand the existing areas were rated in accordance with the minimum requirements.

Applying the model to the existing areas shows that they largely meet the temperature requirements at least to an adequate extent. Nevertheless there are also areas currently used for viniculture at thermally rather unfavourable locations. These are mainly on elevated slopes in the tributary valleys of the rivers Ruwer and Mosel. Some vinicultural areas in current use are also at locations threatened by frost. A liberalisation could prove to have a negative effect on these areas [40,41]. As a consequence of liberalisation acreage at locations with rather unfavourable prevailing climatic conditions or high production costs would probably be among the first to be taken out of production and replaced by more favourable areas. Experts familiar with these areas have confirmed the plausibility of these analyses. Furthermore, adaptations in regards to vines planted will guide managerial decisions [42,43].

Scenarios made on the basis of climate simulations which project a more intensive warming as well as assuming higher thresholds for the water supply result in an indication of vineyard acreage potential to a similar extent to that yielded by the basic model.

\section{Conclusion}

Despite a stable vineyard area German wine production is characterized by ongoing structural changes. Production is and will also be influenced by climate change. Some vine regions will suffer with the need to adapt and some areas could win. The simulation model delivered a map of agricultural surface for the region Rhineland-Palatinate considering the relevant parameters for growing vine. The model excludes areas that do not fit for wine growing due to current regulative restriction (e.g. nature protection areas), insufficient thermal or humidity conditions, high risk areas of natural hazards negatively impacting wine cultivation (e.g. frost), or failing basic requirements for efficient cultivation (e.g. minimal lot size). Considering all the restrictions the potential surface to grow wine in Rhineland-Palatinate could be expanded from the currently planted 66,000 to about 200,000 ha. Cropland hence is not the restricting factor in liberalization efforts. Climate change might even justify more liberal treatment of planting rights to flexibly identify the best vine cultivation landscape alongside the implications of climate change.

A far-reaching liberalization therefore could allow for massive planting of vines but with the need to substitute other crop. Surely, the low profitability of the wine industry, entrepreneurial risks, investment magnitude, or substitution of less favourable vineyards by better lots will result in only partial exploitation of the overall potential. Still, there is a risk of overproduction if too much area will be planted with wine and in the light of years with lower yields the ambition to increase output will lead entrepreneurial decisions without long term view on overall production. On the other hand, flexibility might support superior resource allocation. Apparently, climate change and historic decisions resulted in planting in areas that might be substituted with more suitable ones in case of liberalized market conditions. Overall, future structural changes might be sped up in case of massive changes in the framework. The analyses illustrate that nowadays superior risk management based on data and simulations should become common practice for the wine growers.

\section{References}

[1] OIV, Statistical report on world vitiviniculture 2012, (2012).

[2] OIV, World Statistics, Porto, (2011).

[3] OIV, Statistical report on world vitiviniculture 2013, (2013).

[4] Europäischer Rechnungshof, Reform der gemeinsamen Marktorganisation für Wein: bisher erzielte Fortschritte, Luxemburg, (2012).

[5] C. Schrader, Reputation und Kaufverhalten : eine empirische Analyse am Beispiel der Vermarktung deutscher Weine in Großbritannien, 312 (2008).

[6] M. Bogonos, B. Engler, S. Dabbert, J. Oberhofer, M. Dressler, How liberalization of planting rights will affect wine sector of Rheinland-Pfalz: a partial equilibrium analysis, Princeton, (2012).

[7] Red., Änderung des Weingesetzes - Umsetzung des EU Genehmigungssystems, Das Deutsche Weinmagazin (2015) 3 .

[8] H. Seibert, Wenn der Anbaustopp fällt, Das Deutsche Weinmagazin 14 (2011) 3.

[9] H. Seibert, Es bewegt sich was, Das Deutsche Weinmagazin 19 (2012) 3.

[10] H. Seibert, Anbaustopp ist keine Planwirtschaft, Das Deutsche Weinmagazin 11 (2012) 3.

[11] H. Seibert, Diskussion um Pflanzrechte geht weiter, Das Deutsche Weinmagazin 3 (2013) 3.

[12] H. Seibert, Wie geht es weiter mit den Pflanzrechten, Das Deutsche Weinmagazin 1 (2013) 3.

[13] B. Gass, Horrorszenario für viele Ortenauer Winzer, (2012).

[14] Deconinck Swinnen, The economics of planting rights, AAWE (2013).

[15] M. Bindi, M. Howden, Challenges and opportunities for cropping systems in a changing climate, (2004).

[16] M. Stock, Klimaveränderungen fordern die Winzer, (2005).

[17] M. Petgen, Reaktion der Reben auf den Klimawandel, Schweiz Z Obst-Weinbau 9 (2007) 6-9. 
[18] C. Kölling, L. Zimmermann, Die Anfälligkeit der Wälder Deutschlands gegenüber dem Klimawandel, Gefahrstoffe-Reinhaltung der Luft 67 (2007) 259-268.

[19] F. Schallenberger, Weinbau. Made in Germany. Der deutsche Weinmarkt im Blickfeld, Mainz, 1-36 (2009).

[20] E.B. Poling, Spring cold injury to winegrapes and protection strategies and methods, HortScience $\mathbf{4 3}$ (2008) 1652-1662.

[21] J. Oberhofer, Strategien zur Verminderung von Spätfrostschäden, Neustadt, 62-65 (2012).

[22] D. Molitor, A. Caffarra, P. Sinigoj, I. Pertot, L. Hoffmann, J. Junk, Late frost damage risk for viticulture under future climate conditions: a case study for the Luxembourgish winegrowing region, Australian Journal of Grape and Wine Research 20 (2014) 160-168.

[23] A. Frey, Die reinste Sauna, Frankfurter Allgemeine Sonntagszeitung 32 (2912) 51.

[24] M. Trapp, C. Kotremba, G. Tintrup, Zukunftsprojektionen im Klimawandel, Der Deutsche Weinbau 25-26 (2010) 18-21.

[25] U. Hera, T. Rötzer, L. Zimmermann, C. Schulz, H. Maier, H. Weber, C. Kölling, Klima en détail, LWF aktuell 86 (2012) 34-37.

[26] S. Solomon, Cambridge University Press, Climate change 2007- the physical science basis: Working group I contribution to the fourth assessment report of the IPCC, (2007).

[27] IPCC, On Climate change 2007: The physical science basis, Cambridge, 333 (2007).

[28] P. Huglin, Nouveau mode d'évaluation des possibilités héliothermiques d'un milieu viticole, Comptes rendus des seances (1978).

[29] A.T. DeGaetano, B.N. Belcher, Spatial interpolation of daily maximum and minimum air temperature based on meteorological model analyses and independent observations, Journal of Applied Meteorology and Climatology 46 (2007) 1981-1992.

[30] G.L. Johnson, C. Daly, G.H. Taylor, C.L. Hanson, Spatial variability and interpolation of stochastic weather simulation model parameters, Journal of Applied Meteorology 39 (2000) 778-796.
[31] L.G. Kovács, P.L. Byers, M.L. Kaps, J. Saenz, Dormancy, cold hardiness, and spring frost hazard in Vitis amurensis hybrids under continental climatic conditions, American journal of enology and viticulture 54 (2003) 8-14.

[32] M. Trought, G. Howell, N.J. Cherry, Practical considerations for reducing frost damage in vineyards, (1999).

[33] D. Johnson, G. Howell, Factors influencing critical temperatures for spring freeze damage to developing primary shoots on Concord grapevines, American journal of enology and viticulture 32 (1981) 144-149.

[34] W. Lähne, Gutachten über das Frostgefährdungspotenzial im Muldenlagenbereich des Wasser- und Bodenverbandes Neustadt-Duttweiler, Maikammer, (2013).

[35] J. Eitzinger, M. Štastná, Z. Žalud, M. Dubrovský, A simulation study of the effect of soil water balance and water stress on winter wheat production under different climate change scenarios, Agricultural Water Management 61 (2003) 195-217.

[36] M. Richenhagen, Wir brauchen die Agrarrevolution, 13 (2011).

[37] J. Oberhofer, Agrarbericht 2011: Gewinne regelrecht eingebrochen, Der Deutsche Weinbau (2011) 26-31.

[38] J. Oberhofer, Faßweinbetriebe sind 2011/12 die Gewinner, Der Deutsche Weinbau (2012) 22-25.

[39] J. Oberhofer, Agrarbericht 2012: Erfreuliche Entwicklung an der Mosel, Der Deutsche Weinbau (2013) 14-19.

[40] A.C. Malheiro, J.A. Santos, H. Fraga, J.G. Pinto, Climate change scenarios applied to viticultural zoning in Europe, Climate Research 43 (2010) 163-177.

[41] A.C. Malheiro, J.A. Santos, J.G. Pinto, G.V. Jones, European Viticulture Geography in a changing climate, OIV Bulletin 85 (2012) 15-22.

[42] M. Wirtz, W. Wagenhahn, Bergauf? Oder bergab?, 162-164 (2010).

[43] D. Hoppmann, B. Berkelmann-Loehnertz, Prognosis of phenological stages of Vitis vinifera ( $c$ v. Riesling) for optimizing pest management*, EPPO Bulletin 30 (2000) 121-126. 